\title{
Student Actions and Community in Online Courses: The Roles Played by Course Length and Facilitation Method
}

\author{
Carrie Demmans Epp \\ University of Pittsburgh \\ Krystle Phirangee and Jim Hewitt \\ University of Toronto
}

\begin{abstract}
Fostering a strong sense of community among students within online courses is essential to supporting their learning experience. However, there is little consensus about how different facilitation methods influence students' sense of community or behaviors. This lack of understanding means instructors do not have the information they need to select an appropriate facilitation method when teaching online. This challenge is further complicated by a poor sense of how community building is influenced by the length of an online course. To better understand the relationship between these factors, we explored students' sense of community across four graduate-level online courses. Two of these courses employed an instructor-led form of facilitation and two employed a peer-led form of facilitation. For each facilitation method, one course lasted an entire term (12 weeks) and the other lasted half a term (6 weeks). This two-by-two betweensubjects design is augmented with interview data. This design enabled the study of both variables and possible interaction effects. The findings revealed students in instructor-facilitated courses experienced a stronger sense of community. Longer courses were also associated with a stronger sense of community, although the relationship was weaker than that of facilitation. No interaction effects were detected between facilitation method and course length. Follow-up analyses examined the relationship between facilitation style, course length, and a set of twelve student behaviors (e.g., note writing, note reading, and replying). The results revealed that both facilitation style and course length were associated with differences in students' note attributes including note length, the Flesch-Kincaid grade level of the text, and the frequency of their replies. Collectively, these findings offer evidence that both facilitation style and course length are related to students' sense of community and the behaviors they exhibit online.
\end{abstract}

Keywords: Online learning environments, community, facilitation method, course length

Demmans Epp, C.; Phirangee, K. \& Hewitt, J. (2017). Student actions and community in online courses: The roles played by course length and facilitation method. Online Learning, 21(4), 53-77. doi: 10.24059/olj.v21i4.1269 
Student Actions and Community in Online Courses:

The Roles Played by Course Length and Facilitation Method

\section{Student Actions and Community in Online Courses: The Roles Played by Course Length and Facilitation Method}

Distance learning was originally created with the hope of educating those who were denied access to education (Ticknor as cited in Harting \& Erthal, 2005). Today, it holds the potential to meet the needs of people who cannot attend on-campus courses because of family and work obligations (Hirshhorn, 2011). With the increasing pressure to provide quality online learning experiences (Thompson \& MacDonald, 2005), many instructors have become cognizant of the need to support the social dimension of learning. They recognize the importance of encouraging student interaction (Hew, 2015) and the adoption of practices that foster a sense of community, that is, a sense of belonging and interactivity in an online learning environment (Rovai, 2002a; Liu, Magjuka, Bonk, \& Lee, 2007; Ouzts, 2006), because community is believed to enable a collaborative, supportive, and positive learning experience (Palloff \& Pratt, 2007).

Current research suggests fostering a sense of community in online courses helps minimize feelings of isolation (Rovai, 2002a), build camaraderie (Conrad, 2005), improve student outcomes (Drouin, 2008), and lead to deeper learning (Hulon, 2013). According to theories of social constructivism, learning is fundamentally a social process and knowledge is developed through interaction (Vygotsky, 1978). New understandings and knowledge emerge when learners negotiate meaning by redefining their own ideas while considering the ideas of others (Richardson, 2003). Such processes can be encouraged in online courses through the development of a course-wide learning community (Song \& McNary, 2011), where community members are responsible for sharing knowledge, co-developing ideas, and supporting one another.

How to best facilitate students' sense of community is a question that requires extensive research. In this paper, we examine the impact of two factors: length of course (regular twelveweek courses vs. concentrated six-week courses) and facilitation method. For the latter, we compared two broad facilitation methods: peer-facilitation and instructor-facilitation. Both methods of facilitation are consistent with socio-constructivist approaches, but they place different responsibilities on the stakeholders. In instructor-facilitated courses, the instructor is responsible for managing many of the aspects of the discourse process, whereas in peer-facilitated courses, the instructor takes a background role and allows students to manage their online discourse (Hew, 2015). It is not clear which facilitation style is pedagogically superior. As a result, some scholars are questioning which role the instructor should adopt (Arend, 2009; Correia \& Baran, 2010).

To make headway on these problems, the current study employs a mixed-methods explanatory design to uncover how students' sense of community is related to facilitation style and course length. It also examines the relationship between facilitation style, course length, and the incidence of specific linguistic behaviors exhibited online, such as the sophistication of their prose as represented through the Flesch-Kincaid grade level, and student forum posting behaviors.

\section{Review of Related Literature}

A wealth of previous research has explored how online courses might be better designed to support student learning and their engagement in communal discourse. A variety of factors have been considered, including discussion group size (Hewitt \& Brett, 2007; Rovai, 2007), facilitation methods (MacKnight, 2000; Rovai, 2007; Wise \& Chiu, 2011), course length (Ferguson \& DeFelice, 2010; Seamon, 2004), and software design (Brooks, Panesar, \& Greer, 2006; Hewitt, 
2005; Swan, 2004). In this paper, we focus on two of these factors: course length and facilitation method. We begin by reviewing the literature on each of these topics.

\section{Course Length}

Many post-secondary institutions offer intensive courses that have the same curriculum as regular courses but take place over half of a semester instead of a full semester. This is typically achieved by scheduling classes twice as often, so the same amount of material can be covered in half the time. For example, a course taught during a regular fall semester might consist of twelve classes, taught once per week, while the same course taught in an accelerated summer term might require only six weeks, with two classes scheduled each week.

Prior research on course length has largely focused on face-to-face courses. As Anastasi (2007) observes, instructors generally assume courses are less effective when offered in an intensive format. However, the literature offers little evidence to support this assumption (e.g., Anastasi, 2007; Austin \& Gustafson, 2006; Daniel, 2000; Seamon, 2004). Most studies have failed to find significant differences between the two formats. In cases where a difference is found, the intensive courses tend to be superior (Seamon, 2004), with students in short courses earning higher mean grades when the same course was compared across lengths (Ferguson \& DeFelice, 2010). This pattern held even when controlling for a variety of individual student attributes such as GPA, age, and affinity for learning (Seamon, 2004). It appears there is little evidence to support the assumption that condensed or short courses are less effective than full-length or long courses, and compelling evidence exists that they may be more effective.

In addition to studying the relationship between course length and student grades, some researchers have examined how course length relates to student satisfaction (Richardson, Maeda, Lv, \& Caskurlu, 2017). While there is a relationship between student satisfaction that varies by online course length (Richardson et al., 2017), the findings from investigations directly comparing courses of different lengths are less clear. One study of online courses by Ferguson and DeFelice (2010) found students in a shorter intensive course were significantly more satisfied with studentstudent communication than those in the longer full-semester version of the course were, but they were less satisfied with student-professor communication. The same researchers detected no significant differences in terms of the students' perceived learning or their intentions to take additional online courses in the future (Ferguson \& DeFelice, 2010). Anastasi (2007), in contrast, found that student ratings of instructors were similar across the two conditions, although they rated the intensive short courses as more challenging. Scott (2003) suggests student satisfaction is highly dependent upon the skill of the instructor, arguing that it is important to establish an atmosphere and relationships early in a short course to help students stay focused and perform better. While Scott (2003) was referring to face-to-face courses, it is plausible to suggest online instructors might need to be similarly prepared to adapt their instruction to an accelerated schedule.

Considered collectively, the literature offers no evidence that intensive courses are less effective than full semester courses, and some studies suggest an intensive course format can yield superior academic results. However, most of the research in this area is concerned with studies conducted on face-to-face courses, and that done in online settings has largely ignored many of the aspects of how the course is managed, making the applicability of these findings to online courses less clear. 
Student Actions and Community in Online Courses:

The Roles Played by Course Length and Facilitation Method

\section{Facilitation Methods}

The educational literature describes many different strategies for facilitating asynchronous online discussions (e.g., Ghadirian \& Ayub, 2017; MacKnight, 2000; Rovai, 2007; Wise \& Chiu, 2011). The current study is concerned with two broad categories of facilitation described by Hew (2015): peer facilitation and instructor facilitation. Instructor facilitation involves the instructor taking responsibility for moderating the ongoing class discussions. This is the traditional role played by instructors in online courses (Hew, 2015). Peer facilitation, in contrast, involves turning over most of the moderating duties to students.

Some scholars struggle with the idea that instructors should facilitate online courses (Arend, 2009; Correia \& Baran, 2010) in part because of the amount of time required to properly monitor student discussions (Correia \& Baran, 2010), and in part because they feel that a peerfacilitated approach confers educational advantages. The proposed educational advantages are twofold. First, peer facilitation is thought to engage students at a deeper cognitive level. The reduced involvement of the instructor requires students to take ownership of high-level cognitive processes, such as synthesizing and summarizing content, challenging and negotiating ideas, relating course content to personal experiences, and posing meaningful questions (Belcher, Hall, Kelley, \& Pressey, 2015). Second, peer facilitation reduces the instructor's "authoritarian presence" in the discourse (Rourke \& Anderson 2002, p. 4), thereby fostering more open, authentic discussion among students. Indeed, some research suggests students feel more comfortable expressing their opinions in peer-facilitated discussions (Baran \& Correia, 2009; Bull, Greer, McCalla, \& Kettel, 2001; Cheung \& Hew, 2010; Correia \& Davis, 2007; Rourke \& Anderson, 2002). Limited evidence suggests students may post longer messages and post messages more frequently (Poole, 2000). However, other studies have shown the quality of peer facilitation can vary widely (Ghadirian \& Ayub, 2017) depending upon the skills of the peer facilitators.

Other researchers argue that an instructor-led approach is preferable in many situations (Hew, 2015; Phirangee, Demmans Epp, \& Hewitt, 2016b). West (2010) asserts that both instructors and students are responsible for developing the connections that define a community. Students' sense of connectedness and learning are related to instructors having a strong presence, and taking an active role in guiding discourse (Shea, Li, \& Pickett, 2006). This perspective is supported by Hew's (2015) study of three different populations taking online courses: full-time undergraduates $(n=39)$, full-time postgraduate diploma students $(n=65)$, and practicing professionals in training settings $(n=64)$. Hew (2015) discovered students in all three groups tended to prefer instructor facilitation to peer facilitation. When asked to explain their preferences, students reported instructors were better at keeping discussions on track, were better positioned to resolve disputes, had better knowledge of relevant information and resources, and were more skilled at reviving discussions when participation began to wane (Hew, 2015). In general, learners had more confidence in the knowledge and the expertise of instructors. Students only preferred peer facilitation in situations where they wanted greater freedom to explore a variety of different perspectives or wanted more say in determining the topics that would be discussed (Hew, 2015).

\section{Summary}

The aforementioned research provides a good understanding of how facilitation style and course length may impact online learning. However, there are several notable gaps in the literature. The research comparing learning across course lengths has focused primarily on face-to-face courses. Investigations of facilitation style and online course length have tended to focus on student 
perceptions rather than behaviors, and the combined influence of course length and facilitation method has not been explicitly explored. In an effort to shed light on these gaps, we posed the following research questions:

- How does student sense of community differ based on online course length and facilitation method?

- How do student behaviors differ based on online course length and facilitation method?

Through an exploration of these questions, we hope to deepen our understanding of how online courses can be designed to enhance student sense of online community.

\section{Methods}

This study employed a mixed-methods explanatory design to explore how the length of online courses and the facilitation method used to support student learning interact with respect to student experiences and behaviors. The study used archival data that had been purposively sampled from a larger project exploring students' sense of community in online learning.

In keeping with this study's goal, students' sense of community and student behaviors within an online learning environment (i.e., the PeppeR learning management system) were considered the dependent variables. The independent variables were the facilitation method instructors chose to use in their online course and the number of weeks the course was scheduled to last. In addition to these measures, interview data was used to help explain differences between study conditions.

\section{Participants}

Four online graduate courses were selected from those offered at a research-intensive North American university. These seminar-style courses were offered in the same faculty of education and used PeppeR. These courses were purposively sampled to ensure equal representation of short courses, which lasted 6 weeks, and long courses, which lasted a full term (12 weeks). Because archival data was being used, the courses were also selected to ensure equal representation of facilitation methods across course lengths. That is, one long course and one short course employed instructor facilitation to manage student discourse through the online learning environment. The other two courses used peer-facilitation.

There were 67 students registered in these courses: 32 students were enrolled in instructorfacilitated courses and 35 were enrolled in peer-facilitated courses. A similar split was found between short $(n=31)$ and long $(n=36)$ courses.

\section{Classroom Community Scale}

Rovai's (2002b) classroom community scale (CCS) was used to measure learner sense of community because it is an established and reliable instrument, as indicated by the reported Cronbach's alpha $(\alpha=.93)$.

The CCS was distributed near the end of the term to all the students enrolled in participating courses: $64 \%$ of students completed the questionnaire. This response rate is well above commonly reported response rates, which range from below $20 \%$ (Fowler, 2009) to the typically observed response rate of $33 \%$ in higher education contexts (Nully, 2008). 
The standard scoring procedures were followed for the CCS as well as its connectedness and learning subscales. For this scale, connectedness refers to "the feelings of the community of students regarding their connectedness, cohesion, spirit, trust, and interdependence" (Rovai, 2002c, p. 325). In other words, connectedness is about students' sense of belonging and feeling comfortable to be an active member because the community accepts them. Learning refers to the "feelings of community members regarding interaction with each other as they pursue the construction of understanding and the degree to which members share values and beliefs concerning the extent to which their educational goals and expectations are being satisfied" (Rovai, 2002c, p. 206-207).

Student scores on each of these scales were then divided by the maximum possible score for that scale to obtain a percentage score. We report these percentages because they are easier to interpret, with higher numbers being better, and provide the full picture. Mean and standard deviation are used to describe student responses since the data was normally distributed. Two-Way ANOVA tests were used to look for differences between groups after checking to see if the data met the necessary assumptions (i.e., normality and equality of variances).

\section{Interviews}

Archival interview data from students and instructors were used for this study. Participants were invited via email to take part in one-on-one semi-structured interviews that focused on instructor and student perspectives of their online experiences and the course they had participated in. All instructors and one student from each course were interviewed. Researchers purposefully selected four students (one per online course) in order to go more in-depth with each participant's experiences in and perceptions of online courses (Creswell \& Clark, 2011).

The analysis first examined the transcriptions to determine the facilitation method that had been employed in each course. Hew's (2015) definitions were used to determine whether the online course had been instructor- or peer-facilitated. The second analysis examined the transcriptions to explain the patterns found in the quantitative data relating to student behaviors, which provided insight into why students may have behaved in certain ways.

\section{Student Activity Measures: System Logging}

In PeppeR, students interact with each other using both notes and private messages. Notes are text-based posts on a class-wide discussion board that can either stand alone or be designated as a reply to an earlier note. Notes generally have a single author, but students can choose to share authorship with others if they like. In some cases, students can post notes on the discussion board that only a select subset of their peers can see. These notes are referred to as private shared notes. In addition to notes, students can send private messages to other people in their class through a messaging system that operates in a fashion similar to email. Unlike notes, which are visible to the entire class, a message is a directed form of communication and it is strictly used for private exchanges.

Each student note and each student message is saved in a time-stamped record in a database. For the current study of student activity, we examined the following note and message measures:

- Notes per week: The number of discussion forum posts an author makes each week.

- Private shared notes by week: The number of posts the author chooses not to make public, but instead shares with a subset of his or her peers. Those who have access to the note can edit it. 
- Notes re-read per week: The number of times an author re-visits a note each week. The first view of the note is excluded from this measure regardless of when this view occurred.

- Edits per note: The number of times an author revises and saves a note.

- Words per note: The average length of an author's notes in number of words.

- Sentiment: The mean amount of emotional vocabulary present in an author's notes as determined using Linguistic Inquiry and Word Count (LIWC).

- Grade level: The mean Flesch-Kincaid grade level of an author's notes. This represents how much education one needs in order to understand what an author has written.

- Replies (\%): The percent of notes written by a student in reply to another note.

- Likes received per note: The average number of likes an author's notes received. A like in PeppeR works in a fashion similar to that in Facebook or other social media environments.

- Likes created per note read: The proportion of the notes that a learner both read and liked, relative to the total number of notes read.

- Links created per note: The number of times an author links from their own notes to other people's notes, relative to the total number of notes the author has written. Links can be thought of as similar to social-media tags.

- Messages to instructors by week: The number of private email-like messages sent from a student to the instructor.

Many of the preceding measures have been employed by other studies as measures of student online activity (e.g., Davie, 1988; Guzdial, 1997). These measures are unitized (i.e., measured on a per-week or per-note basis) to permit more meaningful comparisons between courses of different lengths or sizes.

Since prior research suggests student behaviors vary based on the course facilitation method (Phirangee et al., 2016b) or length (Haythornthwaite, Kazmer, Robins, \& Shoemaker, 2006), the log data were analyzed to explore whether student behaviors varied based on these attributes. Mean and standard deviation are used to describe student behaviors. A 2-Way ANOVA was not used to look for group differences because the data did not satisfy all the assumptions upon which this statistical test is based. As a result, the non-parametric equivalent of a t-test, the Mann-Whitney $U$ test, is used to see whether there are differences between groups based on course length or facilitation method. Graphical approaches are then used to investigate whether course length and facilitation method interact for each of the logged behaviors (dependent variables).

\section{Results}

\section{Classroom Community Scale}

Student responses (see Table 1) to the CCS were reliable $(\alpha=.90)$, as were their responses to its connectedness $(\alpha=.88)$ and learning subscales $(\alpha=.83)$. This reliability allowed for the further analysis of any differences that may have existed based on course characteristics that include the employed facilitation method and the amount of time the course lasted.

When investigating student connectedness as it is manifested through students' sense of social support, the results of a 2-Way ANOVA revealed a main effect of moderate magnitude approaching significance for the facilitation method employed, $F(1,39)=3.69, p=.065, \eta^{2}=.084$. No significant interaction $(F<1)$ and no main effect of course length, $F(1,39)=2.31, p=.136, \eta^{2}$ 
$=.056$, were found. This suggests the minimum level of social support that is needed to enable the establishment of a sense of community can develop rapidly if the correct conditions are created.

\begin{tabular}{|c|c|c|c|c|c|c|c|c|c|}
\hline \multirow[b]{2}{*}{ Course } & \multirow[b]{2}{*}{ n } & \multicolumn{2}{|c|}{ Learning } & \multicolumn{2}{|c|}{ Connectedness } & \multicolumn{2}{|c|}{ CCS } & \multirow{2}{*}{$\begin{array}{l}\text { Facilitator } \\
\text { Type }\end{array}$} & \multirow{2}{*}{$\begin{array}{c}\text { Term } \\
\text { Length }\end{array}$} \\
\hline & & $M$ & $S D$ & $M$ & $S D$ & $M$ & $S D$ & & \\
\hline 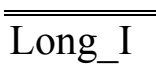 & 15 & 80.62 & 10.13 & 55.83 & 16.88 & 68.23 & 12.95 & Instructor & 12 \\
\hline Short_P & 14 & 58.90 & 15.53 & 40.00 & 17.00 & 49.45 & 13.00 & Peer & 6 \\
\hline Short_I & 17 & 73.75 & 14.75 & 51.58 & 10.60 & 62.66 & 11.39 & Instructor & 6 \\
\hline Long_P & 21 & 68.58 & 10.40 & 49.83 & 13.43 & 59.20 & 10.59 & Peer & 12 \\
\hline
\end{tabular}

Table 1. CCS and Subscale Scores (\%) by Course, Facilitator Type, and Term Length (Number of Weeks)

Another 2-Way ANOVA was used to determine how students' sense of having their learning supported differed based on course length and facilitation method. This test indicated main effects for facilitation method, $F(1,39)=12.07, p=.001, \eta^{2}=.236$, and course length, $F(1,39)=4.57, p=.039, \eta^{2}=.105$. No interaction was found $(F<1)$. Students felt their learning was better supported in instructor-facilitated courses. The facilitation method appears to influence student perceptions more than course length: facilitation method had a large effect size $\left(\eta^{2}>.14\right)$ whereas course length had a moderate effect size $\left(\eta^{2}>.06\right)$. Students in long courses felt their learning was better supported than those in short courses. This may be partly due to their sense of needing interaction to support their learning through exposure to different perspectives and others challenging their ideas. As one student stated,

That person would be able to validate and help you see through what you're reading and doing and make your learning [pause]. Enrich it. Make it more accessible in the sense that you might be able to deconstruct certain ideas with a group and understand it from different perspectives. You might benefit from an enriched experience because other people would suggest different resources that you haven't heard of if you were just doing it by yourself, and I guess knowing that I have the teacher is very important.

To investigate students' overall sense of the strength of their community, the full CCS was analyzed. The two-way ANOVA revealed similar insight to that obtained from the learning subscale. That is, there was no interaction $(F<1)$ and moderate to large main effects were found for both course length, $F(1,39)=4.21, p=.047, \eta^{2}=.097$, and facilitation method, $F(1,39)=8.87$, $p=.005, \eta^{2}=.185$. Again, a stronger sense of community was felt by those taking instructorfacilitated courses and those enrolled in long courses. If we consider the effect sizes $\left(\eta^{2}\right)$ of these two factors, we can see facilitation method plays a larger role than course length for both the CCS and the learning subscale.

While course length had less of an influence on student experience than facilitation method, student interviews indicated course length (6 weeks vs. 12 weeks) may have hindered the development of their sense of community by limiting the interactions they have online with their instructor and peers. For instance, one student emphasized it is more difficult to create community in online summer courses because these courses are shorter, and short courses leave too little time to interact with others and build a sense of community: "So, what I'm saying is that a community 
takes longer to develop sometimes, you know to be created online, especially in the shorter courses, and it doesn't always work for all students, some students won't experience it."

\section{Observed Student Behaviors}

The difference in CCS that is attributed to facilitation method, led us to analyze student actions within the online courses from the perspective of the facilitation method used within each course. The descriptive statistics and results of these analyses can be seen in Table 2 .

\begin{tabular}{|c|c|c|c|c|c|c|c|}
\hline \multirow[b]{2}{*}{ Student Activity } & \multicolumn{2}{|c|}{$\begin{array}{l}\text { Instructor- } \\
\text { Facilitated }\end{array}$} & \multicolumn{2}{|c|}{ Peer-Facilitated } & \multicolumn{3}{|c|}{ Mann-Whitney Test } \\
\hline & $M$ & $S D$ & $M$ & $S D$ & $U$ & $p$ & $r$ \\
\hline Notes per week & $\overline{4.12}$ & 2.59 & 3.03 & 1.32 & 424.50 & .089 & $\overline{0.07}$ \\
\hline Private shared notes by week & 0.03 & 0.07 & 0.10 & 0.22 & 521.50 & .470 & .09 \\
\hline Notes reread per week & 12.79 & 7.79 & 9.30 & 7.26 & 402.50 & .048 & .25 \\
\hline Edits per note & 0.23 & 0.42 & 0.26 & 0.33 & 491.00 & .382 & .22 \\
\hline Words per note & 237.6 & 84.57 & 197.0 & 52.53 & 391.00 & .034 & .25 \\
\hline Sentiment & 6.28 & 0.13 & 6.50 & 0.13 & 123.00 & $<.001$ & .69 \\
\hline Grade level & 11.82 & 1.20 & 10.67 & 1.12 & 282.50 & $<.001$ & .44 \\
\hline Replies (\%) & 48.73 & 25.35 & 77.22 & 12.85 & 163.50 & $<.001$ & .63 \\
\hline Likes received per note & 0.14 & 0.14 & 0.62 & 0.29 & 65.50 & $<.001$ & .78 \\
\hline Likes created per note read & 0.015 & 0.034 & 0.021 & 0.028 & 402.50 & .038 & .25 \\
\hline Links created per note & 0.002 & 0.009 & 0.01 & 0.04 & 514.00 & .277 & .13 \\
\hline Messages to instructor by week & 0.16 & 0.24 & 0.30 & 0.43 & 383.00 & .022 & .36 \\
\hline
\end{tabular}

Table 2. Descriptive and Inferential Statistics of Learner Use of the PeppeR OLE by Facilitation Method

From Table 2, we can see many differences in student activity that are associated with the facilitation method employed in the studied online courses. These differences (Mann-Whitney Test columns) varied from being relatively small $(r<.3)$, as was the case for note rereading and links created per note read, to large $(r>.5)$, as was the case for likes received per note and replies. Those in instructor-facilitated courses created more content (words per note) and that content tended to be more academic (i.e., had a higher grade level) than the content created by those in peerfacilitated courses. In contrast, students in peer-facilitated courses performed more activities that might be associated with creating a sense of connectedness: they expressed more sentiment, liked more of the notes they read, and replied to a greater proportion of the notes they read. However, the higher levels of engagement in activities that should have supported the development of a sense of community did not mean students' learning was sufficiently supported. This lack of support for students in peer-facilitated courses was indicated through the learning subscale of the CCS (see Table 1) and their communicating more with their instructor through private channels (messages to instructor by week). 
Table 3 describes student behaviors based on the length of their course. It also shows the results of inferential statistics comparing long to short courses. The small to moderate $(r<.5)$ differences associated with course length have a smaller magnitude than those associated with facilitation method, where some behaviors differed by a factor of more than four (e.g., likes received per note).

\begin{tabular}{|c|c|c|c|c|c|c|c|}
\hline \multirow[b]{2}{*}{ Student Activity } & \multicolumn{2}{|c|}{ Short } & \multicolumn{2}{|c|}{ Long } & \multicolumn{3}{|c|}{ Mann-Whitney Test } \\
\hline & $M$ & $S D$ & $M$ & $S D$ & $U$ & $p$ & $r$ \\
\hline Notes per week & 3.6 & 1.93 & 3.5 & 2.23 & 517.00 & .606 & .06 \\
\hline Private shared notes by week & 0.13 & 0.23 & 0.01 & 0.028 & 402.00 & .003 & .36 \\
\hline Notes reread per week & 9.2 & 5.60 & 10.8 & 7.92 & 528.50 & .711 & .05 \\
\hline Edits per note & 0.3 & 0.44 & 0.2 & 0.30 & 423.00 & .086 & .21 \\
\hline Words per note & 241.4 & 80.11 & 194.8 & 57.17 & 360.00 & .013 & .30 \\
\hline Sentiment & 6.4 & 0.18 & 6.4 & 0.16 & 530.00 & .725 & .04 \\
\hline Grade level & 11.6 & 1.35 & 10.9 & 1.13 & 373.50 & .020 & .28 \\
\hline Replies (\%) & 47.9 & 23.05 & 77.2 & 15.94 & 121.50 & $<.001$ & .25 \\
\hline Likes received per note & 0.5 & 0.46 & 0.3 & 0.16 & 538.00 & .801 & .03 \\
\hline Likes created per note read & 0.1 & 0.17 & 0.3 & 0.37 & 299.00 & .001 & .42 \\
\hline Links created per note & 0.002 & 0.009 & 0.012 & 0.042 & 515.50 & .314 & .12 \\
\hline Messages to instructor by wee & 0.3 & 0.46 & 0.2 & 0.17 & 494.50 & .412 & .10 \\
\hline
\end{tabular}

Table 3. Descriptive and Inferential Statistics of Learner Use of the PeppeR OLE by Course Length

The differences in student behavior found based on course length are not perfectly aligned with those found when analyzing the data from the perspective of the facilitation method employed. For instance, those taking short courses wrote moderately more private shared notes, but no difference was detected when analyzing the data by facilitation method.

Given the dissimilarities in between-group differences that are found across Table 2 and Table 3, it is likely course length and facilitation method interact with one another. To consider the potential interplay between course length and facilitation method, we graph student behaviors by these factors to better understand their roles. Only behaviors where differences were found for one or both factors were analyzed in this manner.

We begin with the linguistic features of student notes. By mentally extending the lines in Figure 1 and Figure 2, it becomes apparent the slopes of these lines will result in their crossing. This indicates the length of student posts (Figure 1) is influenced by an interaction between course length and facilitation method. Similarly, the Flesch-Kincaid grade-level of student posts (Figure 2 ) is influenced by some combination of facilitation method and course length. 


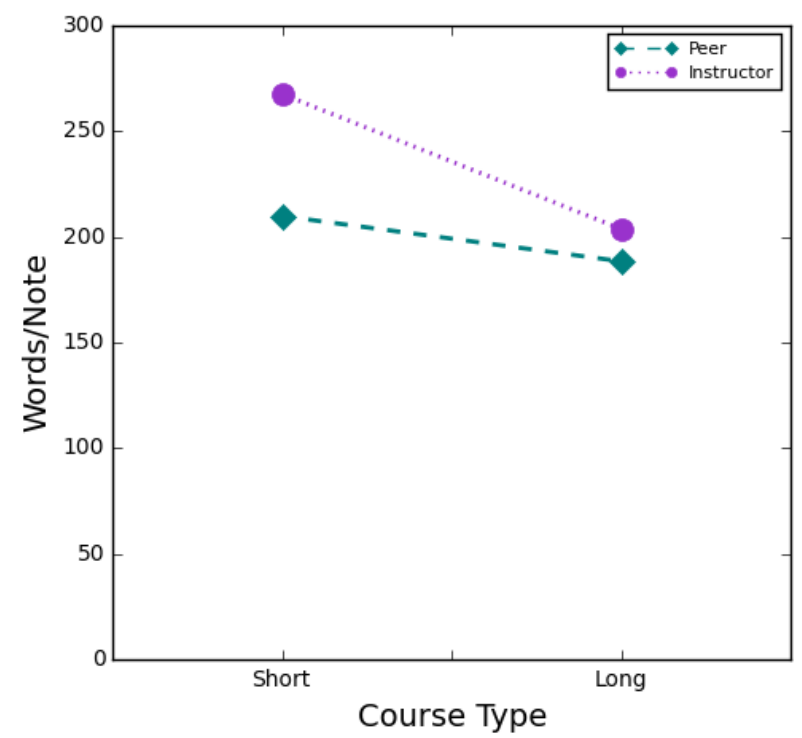

Figure 1. The length of student notes by facilitation method and course type

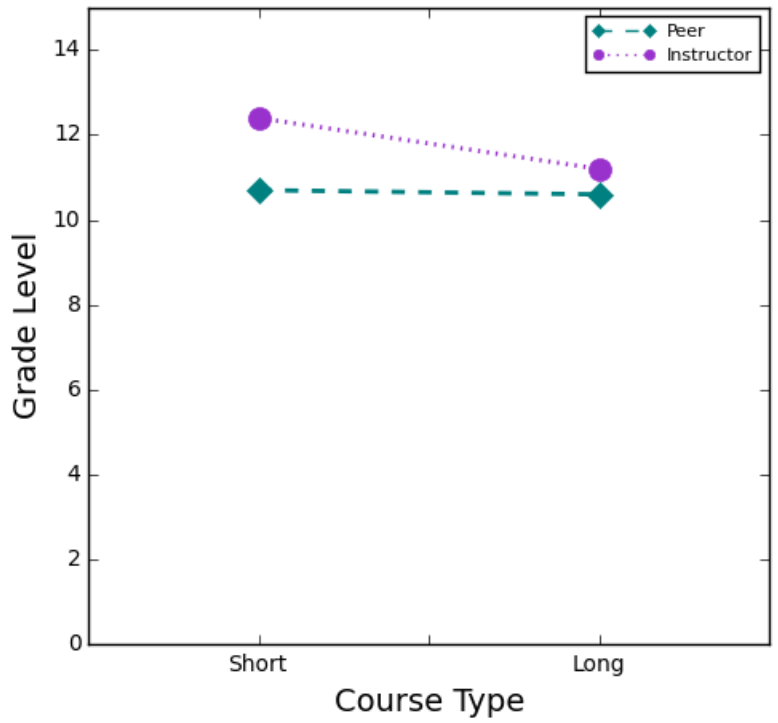

Figure 2. The average grade-level of the writing in student posts

In contrast, the horizontal lines in Figure 3 indicate the higher level of sentiment that is found in students posts from peer-facilitated courses can be attributed to the facilitation method employed, with course length seeming to have no influence on the sentiment expressed in student posts.

Student reading habits (Figure 4), like the grade-level and length of their notes, seemed to be linked to both course facilitation method and course length. The amount of re-reading students performed each week appears to be directly linked to the facilitation method being used, with those from instructor-facilitated courses re-reading their classmates' notes more across course lengths. 
In peer-facilitated courses, student re-reading activities were additionally linked to course length, where they paid more attention to their classmates' notes in longer courses.

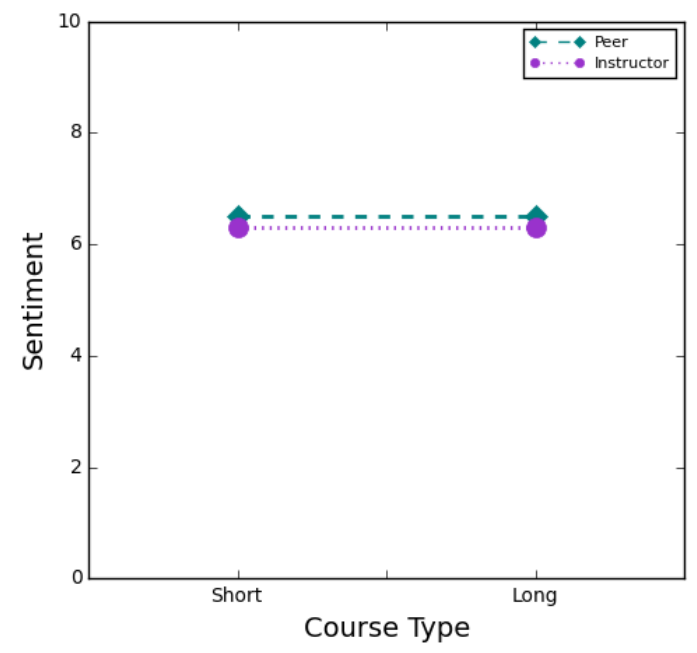

Figure 3. The average sentiment level of student posts

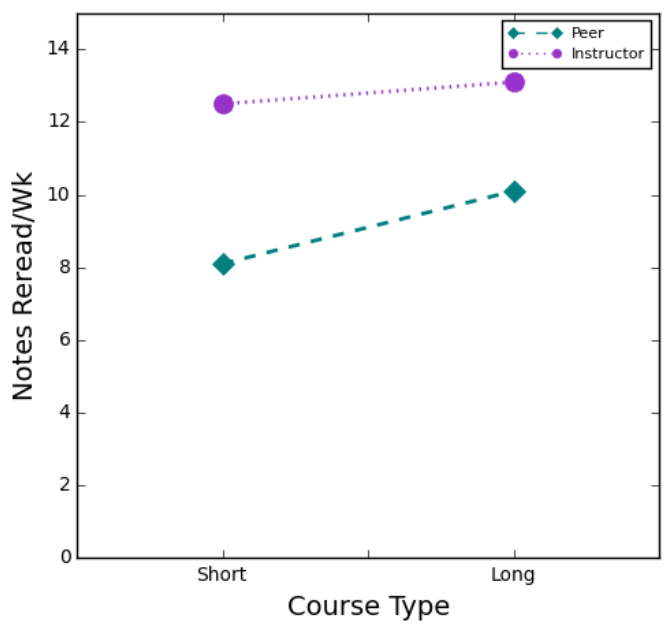

Figure 4. The number of notes students re-read each week

Figure 5 indicates the differences in student reply habits are directly tied to the facilitation method and the length of the course. From this chart, we can see there is a tendency for a smaller proportion of notes to receive replies in short courses. The same is true of instructor-facilitated courses. However, the difference that is tied to facilitation method can be attributed to a feature of how these instructors enacted peer-facilitation: they required students to reply to anyone who had replied to one of their notes. This requirement made the percent of notes replied to artificially high for the peer-facilitated group, especially when considering that specific posting requirements (e.g., number of posts or an obligation to reply to posts in a discussion the student started) were not made explicit for those taking instructor-facilitated courses. 


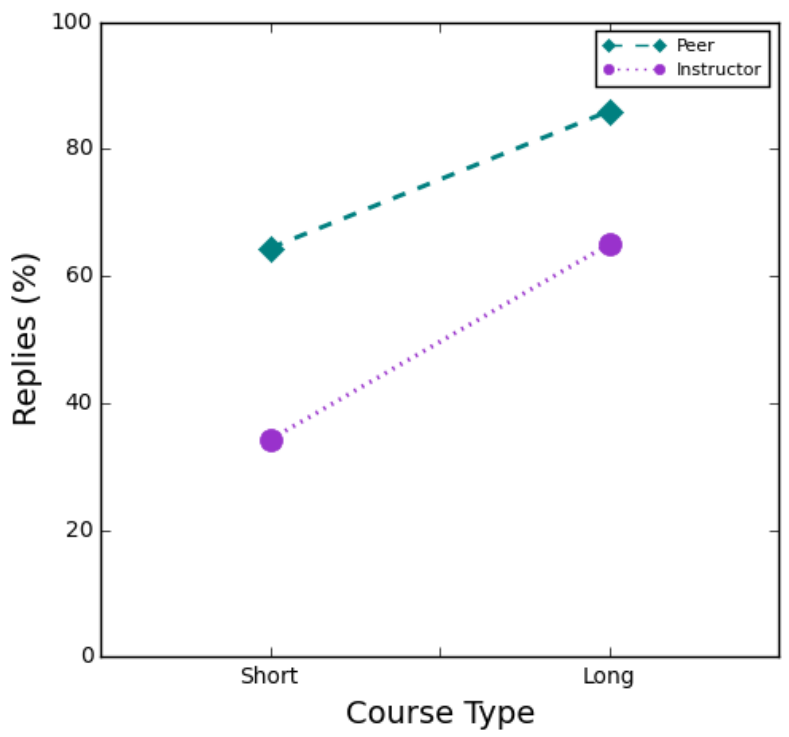

Figure 5. Student replies to their peers as the percent of notes they wrote in response to another

Moving from the above public communication sphere to more private approaches to communicating with instructors and fellow students, the complicated nature of how course length and facilitation method interact becomes apparent. Figure 6 shows how strongly private requests for instructor support are linked to facilitation method in short courses. As one student reported,

If you had questions, he [the instructor] said you could post it on PeppeR which he prefers because others can see it too. But he also said you can email him because some people might be too embarrassed to post or ask their questions publicly. So, he'll write "I've been asked..." and this will be posted in PeppeR without saying who asked the question.

This relationship between course length and facilitation method was absent in long courses, where student requests for instructor support through email-like messages were similar across facilitation methods. This similarity suggests other methods for obtaining support were available in longer courses or students felt less urgency. Student reports of the support mechanisms employed by instructors suggest both factors may have played a role since they knew when they could obtain additional support:

With the phone calls, I felt it was really helpful and she would say these calls were not mandatory and if you don't have any questions feel free to not log in. It's sort of, if you had a question she made herself available. But I called in every time just because I liked to hear what she had to say. 


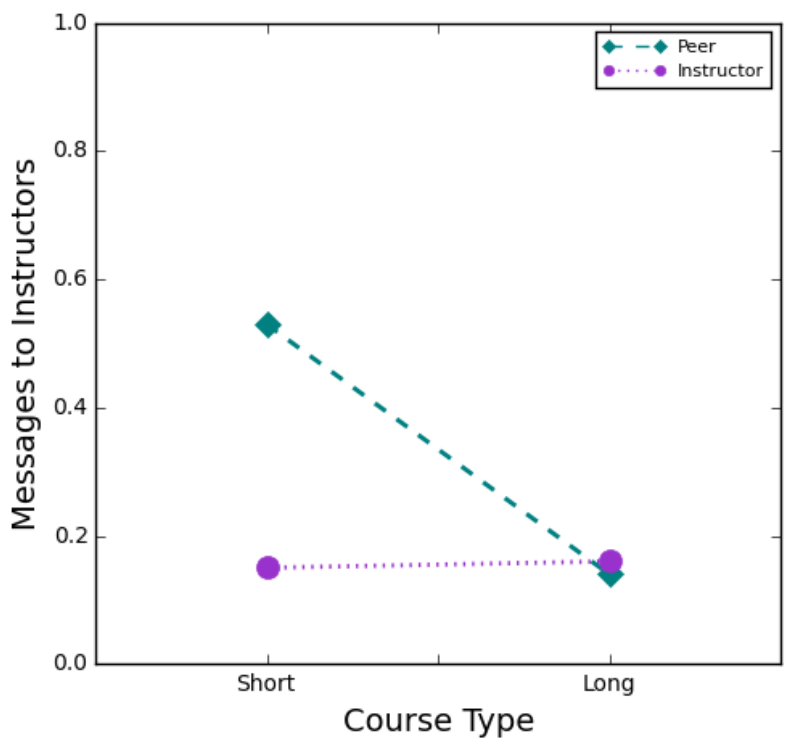

Figure 6. The number of email-like messages students sent to instructors each week

Private communication among students also seems to be influenced by both course length and facilitation method (Figure 7). This type of communication, as seen through students' use of private shared notes, was more common in peer-facilitated courses even though the instructor's lack of involvement might suggest this type of backchannel communication is unnecessary. During the interviews, students indicated they used private channels, such as chat and messaging, for coordinating "assignments and for revolt [laugh]. I'm a distance student living in Montreal, but if I was living closer to the campus I probably would have said 'Hey. Let's meet up. Go for some coffee'." Essentially, students used private communication to deal with problems when they did not want the whole group and instructor to be aware of what was being discussed. Concern over excluding classmates from learning opportunities was also why students resisted the use of other forms of private communication (e.g., messaging and chat tools): "I guess I really wasn't sure if I should. Like would my conversation with that peer take away from the course, maybe our conversation would have been valid for our course and could have helped others." Unlike student sending of messages to instructors, differences in their use of private shared notes across facilitation methods persisted for long courses even though these differences were smaller. This pattern in message sending indicates course length cannot fully close the gap between facilitation methods for this communication behavior. 


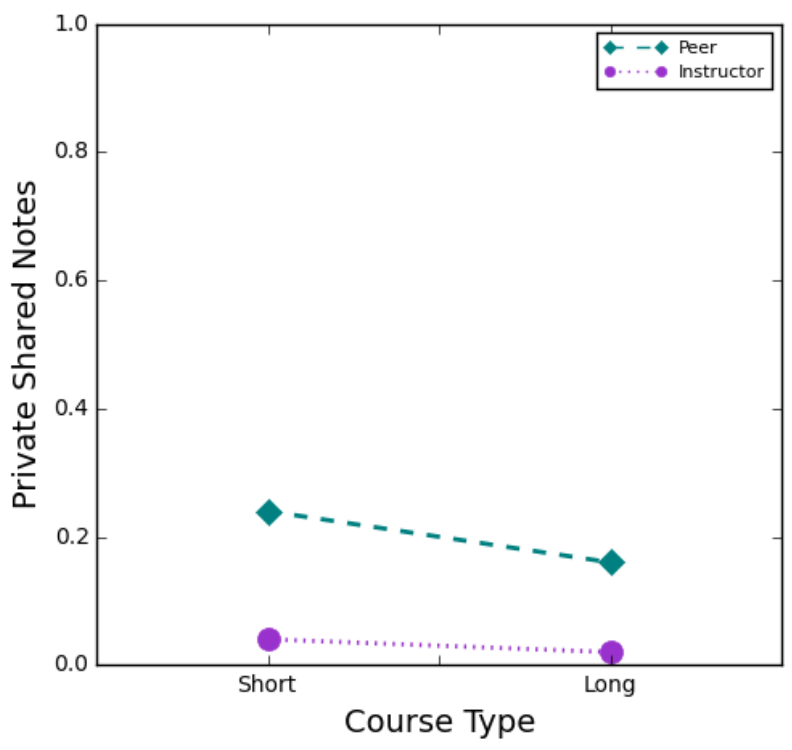

Figure 7. The number of private shared notes students posted

Going beyond the targeted communication that is enabled through private shared notes, use of the like feature holds the potential to support community development. However, like many of the other behavioral measures, course length and facilitation method interact with respect to student liking of others' notes (Figure 8). Those in peer-facilitated courses liked one another's notes less in long courses than they did in short courses. This change in liking behaviors shows how time gives the opportunity for other factors to influence student activities, including whether students provide explicit support to their peers. The more level use of liking by those in instructorfacilitated courses implies instructor involvement encouraged more consistency in student behaviors across conditions.

More dramatic differences are seen in the number of likes students from peer-facilitated courses received (Figure 9) between long and short courses. They also received more likes per note posted than those from instructor-facilitated courses did even though this gap is considerably smaller for long courses. For those who took instructor-facilitated courses, we see a substantial increase in the number of likes they received between short and long courses. This difference suggests students may need time to develop and appreciate their classmates' work or the support provided by those same peers. 


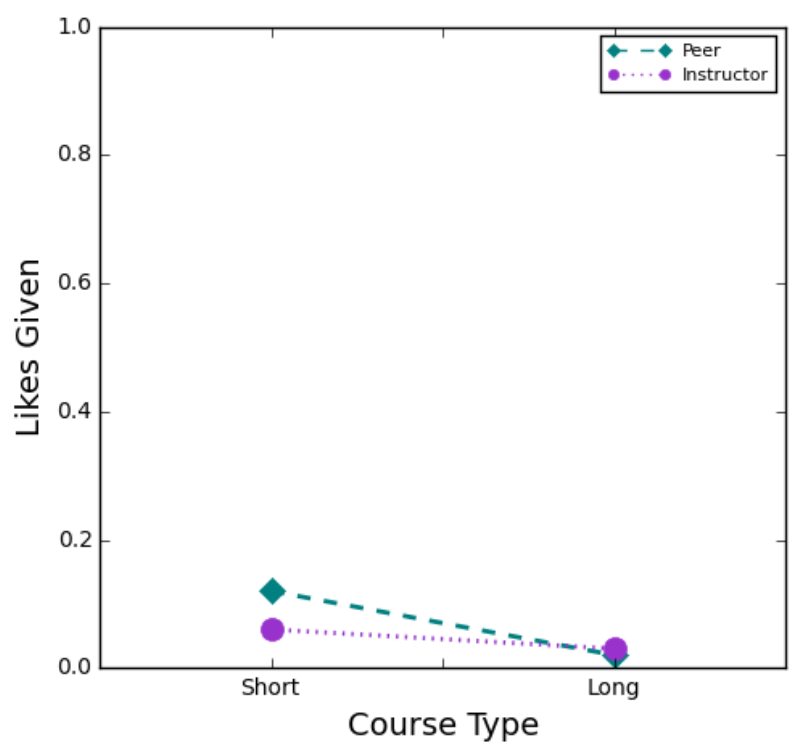

Figure 8. The number of notes students read and liked

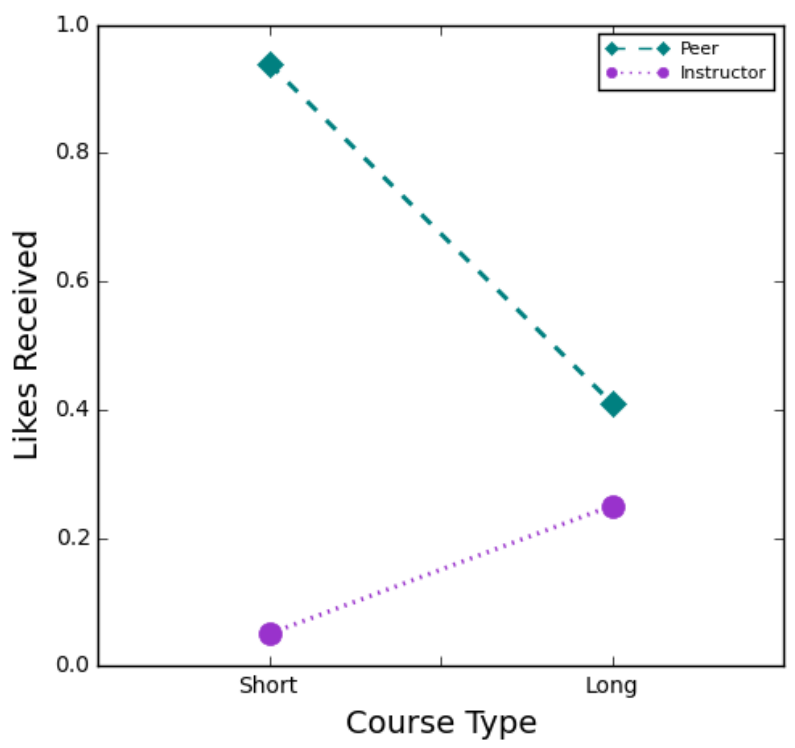

Figure 9. The number of likes students received for each note they posted

\section{Summary}

The preceding research identified several relationships among course length, facilitation method, and students' sense of community. Overall, a stronger sense of community is associated with long courses and the use of instructor-facilitation. For the most part, students' sense of community is stronger because they feel their learning is better supported (as opposed to feeling more connected to others). Collectively, these findings suggest students' sense of community is stronger in long courses and in courses where instructor facilitation is used. 
A deeper look at the facilitation method used revealed student behaviors differed across instructor-facilitated and peer-facilitated courses. Students in instructor-facilitated courses wrote longer notes, wrote at a higher grade level, re-read more notes, expressed less sentiment, and received fewer likes from their classmates. Students in long courses behaved differently than students in short courses in many of the same ways as those observed based on facilitation method. Students in long courses wrote longer notes, wrote at a higher grade level, and gave fewer likes to their classmates. However, there were notable differences (e.g., students in long courses wrote proportionately fewer private shared notes).

Follow-up analyses revealed interactions between facilitation method and course length across the following measures: length of student posts, the average grade-level of student writing, the mean number of notes re-read, the percentage of replies, the number of private messages to instructors, and their use of the like feature. The cause of these interactions is unclear, but it is apparent that both the length of a course and how it is facilitated influenced student behaviors.

\section{Discussion}

The interactions between course length and facilitation method and their moderating effect on several learner behaviors indicate the importance of jointly investigating these two potential influences on student behavior. However, the majority of prior work has not considered the joint relationship of these variables with student behaviors in online learning environments. For this reason, we discuss our results in light of research considering either facilitation method or course length. Where possible, we also compare findings from this study to those that considered both factors.

When considering facilitation method, several student behaviors were consistent with prior work. Similar to the results reported by Phirangee and colleagues (2016a), those taking instructorfacilitated courses were observed re-reading their classmates' notes more than those in peerfacilitated courses. This activity is consistent with the types of online listening practices that are associated with discourse that supports collaborative learning (Wise, Hausknecht, \& Zhao, 2014). The additional exhibition of a greater sense of community among those in instructor-facilitated courses is consistent with prior results showing the strong relationship between behaviors that are indicative of teaching presence, such as instructor involvement in the forums, and students' sense of community (Shea, $\mathrm{Li}, \&$ Pickett, 2006). This type of instructor involvement is argued to promote collaboration (Agosto, Copeland, \& Zach, 2013), which can lead students to feel more supported and like they belong to a learning community.

The higher use of sentiment, lower grade level, higher response rate, greater use of liking, and higher number of messages sent to instructors by students from peer-facilitated courses were also consistent with Phirangee et al.'s (2016a) results. Although students seem to support their peers (i.e., response rate and liking), the lower grade level and higher number of messages to the instructor seem to indicate that students need the instructor's guidance, input, and support in understanding and dissecting the content. This aligns with Hew's (2015) findings of students viewing the instructors as the "subject matter experts" who are able to keep discussions on topic, ensure equity, and guide learning more effectively.

Several student behaviors were inconsistent with prior results from studies investigating the relationship between facilitation method and student behaviors (Phirangee et al., 2016b). These 
inconsistencies (e.g., student posting and editing habits or their linking to others' posts) are partially attributable to limitations in the study design. The effect sizes associated with these behaviors were too small for differences to be detected given the sample size. However, this is not the only reason differences were not detected. As can be seen by Figure 7 and the private shared notes row in Table 2, course length also played a role in muddling the signal that can be attributed to facilitation method for some of these non-results, thus lending weight to the argument that these variables need to be investigated together if we are to better understand online learning.

It appears course length may have a compensatory influence on some student behaviors. From Figure 4, we can see that both peer and instructor facilitation seem to follow similar paths, with students in both courses rereading their classmates' posts more when taking longer courses. A similar pattern is seen for student replies (Figure 5). However, the slopes of the lines indicate course length may have a stronger influence on student reply habits when the instructor facilitates the course. In contrast, course length seems to have a stronger influence on student rereading habits in peer-facilitated courses, where they may not feel they have the time to pay as careful attention to their peers' posts because they are busy co-managing a discussion and need the first part of the course to coordinate and manage this peer-facilitation process. This difference is further supported by longitudinal research into computer science course forums where "participation of the instructor and of paid tutors ... is critical at the outset of a course to stimulate usage of the system" (Vassileva et al., 2001, p. 419).

Consistent with the theory that time may help compensate for the weaknesses of one approach, several behaviors went from differing for a particular course length and facilitation combination to being the same or aligning for another combination. For example, student sending of messages to instructors is the same across facilitation methods for long courses but three times higher for short peer-facilitated courses (Figure 6). In contrast, student interaction with instructors via the messaging feature was consistent across course lengths for those in instructor-facilitated courses, suggesting these students had more consistent support needs likely because the instructors provided additional support through the forum. Other behavioral alignment, like that from Figure 6 , was observed in student posts. The length of notes from both peer and instructor facilitation decrease from short to long courses (Figure 1), but the steeper slope of the instructor-facilitation condition shows how student notes became shorter to the point where those written in long instructor-facilitated courses were of comparable length to those from short peer-facilitated courses. The grade level of student writing (Figure 2) exhibited a similar pattern for instructor facilitation: long instructor facilitation was comparable to long peer facilitation, but short courses differed between the two facilitation methods. In this case, student behaviors were consistent across course lengths for peer-facilitation. The above evidence suggests course length and facilitation method; both influence certain behaviors which need to be accounted for going forward.

These behavioral patterns suggest it is possible to indirectly encourage particular interactions by selecting the combination of course length and facilitation method that seems to best promote desired behaviors. Encouraging and enabling particular behaviors, such as group awareness and recognition for one's contributions, can help improve student learning experiences and help them become a learning community (Brooks, Panesar, \& Greer, 2006; Vassileva, McCalla, \& Greer, 2016). For instance, the collected data revealed sentiment was only influenced by facilitation method and not by course length, thus highlighting that some interactions are either encouraged or discouraged by the instructor. According to Phirangee and Hewitt (2016), students 
strategically used specific cues such as emoticons, punctuation, and the like button "to express their feelings about the content and peer feedback, as well as to project a particular emotional tone in their online notes" (p.82). Within the larger project from which this data was drawn, these students admitted to feeling conflicted about using such cues in an academic setting, even though it was helpful to their learning and online communication (Phirangee \& Hewitt, 2016). They also likely would have stopped using these explicit signals of their feelings if the instructor had communicated they were perceived as inappropriate or unacademic. Therefore, sentiment, the expression of emotion, and other behaviors seem to be substantively influenced by instructor behavior.

These and other behaviors are known to have relationships with student perceptions of their sense of community and the course facilitation method (Phirangee et al., 2016b). Differences found based on course length expand this understanding and enable the more detailed exploration of student sense of community based on course length and facilitation method. From the results of the classroom community scale, it would appear sufficient group awareness can be created by both facilitation methods regardless of course length since all groups sensed similar levels of social connectedness. This result conflicts with prior reports of an artefact-based measure of group connectedness where those in short courses exhibited greater cohesion than those in long courses (Akyol, Vaughan, \& Garrison, 2011). However, the lack of difference in students' sense of connectedness alongside the differences in the learning support they felt they received indicates enough of a social connection existed to enable their engagement in the online learning community. Unlike students' sense of social connectedness, the perception that their learning was supported, and their overall sense of community differed by condition. Like the results of over a decade of research into computer science course forums (Vassileva et al., 2016), instructor facilitation was associated with higher levels of learning support and a greater sense of being engaged in a learning community. These findings were also consistent with a recent meta-analysis (Richardson et al., 2017): course length was associated with students' sense of learning support and overall sense of community. In our case, longer courses received higher scores than shorter courses.

\section{Limitations}

The instrument used to measure student perceptions is widely used and reliable, but there is limited evidence of the validity of its subscales (Barnard-Brak \& Shiu, 2010). This concern is related to the factor loadings of sub-scale items. However, this scale has been used to measure the level of community development within groups of adult learners (Shea et al., 2006; Rovai, 2002c; Graff, 2006) and teacher-education students (Overbaugh \& Lin, 2006; Dawson, 2006), showing its applicability in spite of its shortcomings.

This small study analyses archival data to gain insight into student learning. The sampling procedures used fail to guarantee the sample was representative of the population, which limits the generalizability of findings. That said, the data was carefully collected and provides evidence for the interaction of two variables that can now be studied using an experimental design to reduce the influence of the confounds that can sometimes arise from exploratory work that uses historical data. 


\section{Conclusion}

Many instructors are familiar with the interactive behaviors that meet learning objectives and support student-learning needs in a classroom-based course. However, teaching online may be unfamiliar territory for some instructors who struggle with choosing task designs to effectively support online learners since teaching approaches used in classroom-based courses may be less effective in online environments (Horspool \& Lange, 2012). If instructors want to foster a sense of community, they need to understand which interactive behaviors are effective across all course lengths and facilitation methods.

To contribute to this understanding, our study introduced course length as a variable influencing student sense of community alongside more traditionally studied variables, including facilitation method and student behaviors. Previous work has considered these factors separately and has described courses by the term in which they were offered (e.g., Shea et al., 2006; Shackelford \& Maxwell, 2012; Dueber \& Misanchuk, 2001; Brown, 2001), student activities (e.g., Drouin, 2008), or facilitation method (e.g., Phirangee et al., 2016a, b). Our findings build on this work by detailing how course length and facilitation method interact, suggesting their joint relationship to several student communication behaviors that include students' reading of classmates' posts, use of private forms of communication, and propensity to respond to their classmates' posts. Our findings build on Phirangee et al. (2016a, b) work by examining the role course length and facilitation method plays in creating a community online. This study confirms students' belief in the critical role instructors play in developing effective communities online. More specifically, students in instructor-facilitated online courses had a higher sense of community and felt their learning was better supported when compared against those in peer-facilitated online courses. These findings further explain the role of course length, which is weaker than that of facilitation method. In this case, greater course lengths were associated with a higher sense of community and learning support. Thus, suggesting connectedness can develop quickly but learning support requires more time and instructor effort. Consistent with our findings, Richardson et al.'s meta-analysis (2017) found social presence and student satisfaction had a weaker link in short courses, whereas social presence and perceived learning had a stronger relationship in longer courses.

Therefore, we argue the adoption of instructor facilitation is likely to better support student learning and their sense of community, especially in short courses. Knowing students' sense of community is influenced by both the facilitation method used and course length, with the facilitation method playing a larger role, is important for instructors when designing their courses and supporting students in an online context because this can allow them to choose an approach that better promotes the student activities they wish to encourage. 


\section{References}

Agosto, D. E., Copeland, A. J., \& Zach, L. (2013). Testing the benefits of blended education: Using social technology to foster collaboration and knowledge sharing in face-to-face LIS courses. Journal of Education for Library and Information Science, 54(2), 94.

Akyol, Z., Vaughan, N., \& Garrison, D. R. (2011). The impact of course duration on the development of a community of inquiry. Interactive Learning Environments, 19(3), 231246. https://doi.org/10.1080/10494820902809147

Anastasi, J.S. (2007). Full semester and abbreviated summer courses: An evaluation of student performance. Teaching of Psychology, 34(1), 19-22. https://doi.org/10.1080/00986280709336643

Arend, B. (2009). Encouraging critical thinking in online threaded discussions. The Journal of Educators Online, 6(1), 1-23.

Austin, A.M. \& Gustafson, L. (2006). Impact of course length on student learning. The Journal of Economics and Finance Education, 5(1), 26-37.

Baran, E., \& Correia, A-P. (2009). Student-led facilitation strategies in online discussions. Distance Education, 30(3), 339-361. http://dx.doi.org/10.1080/01587910903236510

Barnard-Brak, L., \& Shiu, W. (2010). Classroom community scale in the blended learning environment: A psychometric review. International Journal on E-Learning, 9(3), 303311.

Belcher, A., Hall, B., Kelley, K., \& Pressey, K. (2015). An analysis of faculty promotion of critical thinking and peer interaction within threaded discussions. Online Learning, 19 (4), 37-44. http://dx.doi.org/10.24059/olj.v19i4.544

Brooks, C., Panesar, R., \& Greer, J. (2006). Awareness and collaboration in the iHelp courses content management system. In W. Nejdl \& K. Tochtermann (Eds.), Innovative Approaches for Learning and Knowledge Sharing (pp. 34-44). Springer Berlin Heidelberg. https://doi.org/10.1007/11876663 5

Brown, R. E. (2001). The process of community-building in distance learning classes. Journal of Asynchronous Learning Networks, 5(2), 18-35.

Bull, S., Greer, J. E., McCalla, G. I., \& Kettel, L. (2001). Help-seeking in an asynchronous help forum. In Proceedings of Workshop on Help Provision and Help Seeking in Interactive Learning Environments of the International Conference on Artificial Intelligence in Education (AIED). San Antonio, TX, USA. Retrieved from http://users.sussex.ac.uk/ bend/aied2001/bull.pdf

Cheung, W. S., \& Hew, K. F. (2010). Asynchronous online discussion: instructor facilitation vs. peer facilitation. In C.H. Steel, M.J. Keppell, P. Gerbic \& S. Housego (Eds.), Curriculum, technology \& transformation for an unknown future. Proceedings ASCILITE. Sydney, Australia (pp.179-183). Retrieved from https://repository.nie.edu.sg/bitstream/10497/4658/1/ChuengWS HewKF 2010 a.pdf

Conrad, D. (2005). Building and maintaining community in cohort-based online learning. Journal of Distance Education, 20(1), 1-20. 
Correia, A. P., \& Baran, E. (2010). Lessons learned on facilitating asynchronous discussions for online learning. Educação, Formação \& Tecnologias-ISSN 1646-933X, 3(1), 59-67.

Correia, A. P., \& Davis, N. E. (2007). The design of collaboration in the virtual classroom. In M. Simonson (Ed.), 30th Annual Proceedings of Selected Papers on the Practice of Educational Communications and Technology (pp. 84-87). Bloomington: Association for Educational Communications and Technology. Retrieved from http://www.aect.org/pdf/proceedings07/2007I/07 12.pdf

Creswell, J. W., \& Clark, V. L. P. (2011). Designing and conducting mixed methods research. Thousand Oaks, CA: Sage Publications.

Daniel, E. L. 2000. A review of time-shortened courses across disciplines. College Student Journal 34(2), 298-306.

Davie, L. (1988). Facilitating adult learning through computer-mediated distance education. Journal of Distance Education 3(2), 55-69.

Dawson, S. (2006). A study of the relationship between student communication interaction and sense of community. The Internet and Higher Education, 9(3), 153-162.

Drouin, M. A. (2008). The relationship between students' perceived sense of community and satisfaction, achievement, and retention in an online course. Quarterly Review of Distance Education, 9, 267-284.

Dueber, B. \& Misanchuk, M, (2001). Sense of community in a distance education Course. Paper presented at the Mid South Instructional Technology Conference, 8-10 April, Murfreesboro, TN. [verified 17 Qct 2006] http://bill.dueber.com/ dueber-misanchuk.pdf

Ferguson, J. M., \& DeFelice, A. E. (2010). Length of online course and student satisfaction, perceived learning, and academic performance. The International Review of Research in Open and Distributed Learning, 11(2), 73-84. http://dx.doi.org/10.19173/irrodl.v11i2.772

Fowler, F. J. (2009). Survey research methods (4th ed). Thousand Oaks: Sage Publications.

Graff, M. (2006). The importance of online community in student academic performance. The Electronic Journal of E-Learning, 4(2), 127-132.

Ghadirian, H., \& Ayub, A. F. M. (2017). Peer moderation of asynchronous online discussions: An exploratory study of peer e-moderating behaviour. Australasian Journal of Educational Technology, 33(1), 1-18. https://doi.org/10.14742/ajet.2882

Guzdial, M. (1997). Information ecology of collaborations in educational settings: Influence of tool. In R. Hall, N. Miyake, \& N. Enyedy (Eds.), Computer-Supported Collaborative Learning (pp. 83-90). Toronto, Ontario, Canada.

Harting, K., \& Erthal, M. J. (2005). History of distance learning. Information Technology Learning and Performance Journal, 23(1), 35.

Haythornthwaite, C., Kazmer, M. M., Robins, J., \& Shoemaker, S. (2006). Community Development Among Distance Learners: Temporal and Technological Dimensions. Journal of Computer-Mediated Communication, 6(1), 0-0. http://doi.org/10.1111/j.10836101.2000.tb00114.x 
Hew, K. F. (2015). Student perceptions of peer versus instructor facilitation of asynchronous online discussions: further findings from three cases. Instructional Science, 43(1), 19-38. https://doi.org/10.1007/s11251-014-9329-2

Hewitt, J. (2005). Toward an understanding of how threads die in asynchronous computer conferences. Journal of the Learning Sciences, 14(4), 567-589. http://dx.doi.org/10.1207/s15327809j1s1404 4

Hewitt, J., \& Brett, C. (2007). The relationship between class size and online activity patterns in asynchronous computer conferencing environments. Computers \& Education, 49, 12581271. https://doi.org/10.1016/j.compedu.2006.02.001

Hirshhorn, R. (2011). Assessing the economic impact of copyright reform in the area of technology-enhanced learning. Retrieved from http://www.ic.gc.ca/eic/site/ippddppi.nsf/eng/h ip01074.html

Horspool, A., \& Lange, C. (2012). Applying the scholarship of teaching and learning: student perceptions, behaviours and success online and face-to-face. Assessment \& Evaluation in Higher Education, 37(1), 73-88. http://dx.doi.org/10.1080/02602938.2010.496532

Hulon, S. (2013). Face-to-face discussions versus online threaded discussions: Can we have the best of both worlds? In R. McBride \& M. Searson (Eds.), Proceedings of Society for Information Technology \& Teacher Education International Conference (pp. 577-582). Chesapeake, VA: Association for the Advancement of Computing in Education.

Liu, X., Magjuka, R. J., Bonk, C. J., \& Lee, S. (2007). Does sense of community matter? Quarterly Review of Distance Education, 8, 9-24.

MacKnight, C. B. (2000). Teaching critical thinking through online discussion. Educause Quarterly, 4, 38-41

Nully, D. D. (2008). The adequacy of response rates to online and paper surveys: What can be done? Assessment \& Evaluation in Higher Education, 33(3), 301-314. http://dx.doi.org/10.1080/02602930701293231

Ouzts, K. (2006). Sense of community in online courses. Quarterly Review of Distance Education, 7, 285-296.

Overbaugh, R. C., \& Lin, S. (2006). Student characteristics, sense of community, and cognitive achievement in web-based and lab-based learning environments. Journal of Research on Technology in Education, 39(2), 205-223.

Palloff, R. M., \& Pratt, K. (2007). Building online learning communities: Effective strategies for the virtual classroom. San Francisco, CA: John Wiley \& Sons.

Phirangee, K., Demmans Epp, C., \& Hewitt, J. (2016a). Exploring how peer and instructor facilitation relates to students' activity patterns in online learning communities. In American Educational Research Association (AERA) Annual Meeting. Washington, D.C.: AERA.

Phirangee, K., Demmans Epp, C., \& Hewitt, J. (2016b). Exploring the relationships between facilitation methods, students' sense of community and their online behaviours. Special Issue on Online Learning Analytics. Online Learning Journal, 20(2). http://dx.doi.org/10.24059/olj.v20i2.775 
Phirangee, K. \& Hewitt, J. (2016). Loving This Dialogue!!!! J: Expressing Emotion Through the Strategic Manipulation of Limited Nonverbal Cues in Online Learning Environments. In S. Tettegah and M. McCreery (Eds.), Emotions, Technology, and Learning (vol. 1). New York: Elsevier, 69-85. https://doi.org/10.1016/B978-0-12-800649-8.00010-9

Poole, D.M. (2000). Student participation in a discussion-oriented online course: A case study. Journal of Research on Computing in Education, 33(2), 162 - 177

Richardson, V. (2003). Constructive pedagogy. Teachers College Record, 105(9), 1623- 1640

Richardson, J. C., Maeda, Y., Lv, J., \& Caskurlu, S. (2017). Social presence in relation to students' satisfaction and learning in the online environment: A meta-analysis. Computers in Human Behavior, 71, 402-417. https://doi.org/10.1016/j.chb.2017.02.001

Rourke, L., \& Anderson, T. (2002). Using peer teams to lead online discussions. Journal of interactive media in education, 2002(1). Retrieved from http://jime.open.ac.uk/articles/10.5334/2002-1/

Rovai, A. P. (2002a). Building sense of community at a distance. The International Review of Research in Open and Distance Learning, 3(1), 1-16

Rovai, A. P. (2002b). Development of an instrument to measure classroom community. The Internet and Higher Education, 5(3), 197-211. https://doi.org/10.1016/S1096$\underline{7516(02) 00102-1}$

Rovai, A. P. (2002c). Sense of community, perceived cognitive learning, and persistence in asynchronous learning networks. The Internet and Higher Education, 5(4), 319-332.

Rovai, A. P. (2007). Facilitating online discussions effectively. The Internet and Higher Education 10, 77-88. https://doi.org/10.1016/j.iheduc.2006.10.001

Seamon, M. (2004). Short and long-term differences in instructional effectiveness between intensive and semester-length courses. Teachers College Record, 106(4), 852-874.

Scott, P. A. 2003. Attributes of high-quality intensive courses. New Directions for Adult and Continuing Education, 2003(97), 29-38. https://doi.org/10.1002/ace.86

Shackelford, J. L., \& Maxwell, M. (2012). Sense of community in graduate online education: Contribution of learner to learner interaction. International Review of Research in Open \& Distance Learning, 13(4), 228-249.

Shea, P., Li, C. S., \& Pickett, A. (2006). A study of teaching presence and student sense of learning community in fully online and web-enhanced college courses. The Internet and Higher Education, 9(3), 175-190. https://doi.org/10.1016/j.iheduc.2006.06.005

Song, L., \& McNary, S.W. (2011). Understanding students' online interaction: Analysis of discussion board postings. Journal of Interactive Online Learning, 19(1), 1-14.

Swan, K. (2004). Learning online: current research on issues of interface, teaching presence and learner characteristics. In J. Bourne \& J. C. Moore (Eds.) Elements of Quality Online Education, Into the Mainstream. Needham, MA: Sloan Center for Online Education, 6379. 
Thompson, T. L., \& MacDonald, C. J. (2005). Community building, emergent design and expecting the unexpected: Creating a quality elearning experience. Internet and Higher Education, 8(3), 233-249. https://doi.org/10.1016/j.iheduc.2005.06.004

Vassileva, J., Deters, R., Greer, J., McCalla, G., Bull, S., \& Kettel, L. (2001). Lessons Learned in Deploying a Multi-Agent Learning Support System: The I-Help Experience. In J. D. Moore, C. L. Redfield, \& W. L. Johnson (Eds.), International Conference on Artificial Intelligence in Education (AIED) (pp. 410-421). San Antonio, TX, USA: IOS Press. Retrieved from http://publicat.bham.ac.uk/7565/

Vassileva, J., McCalla, G. I., \& Greer, J. E. (2016). From small seeds grow fruitful trees: How the PHelpS peer help system stimulated a diverse and innovative research agenda over 15 years. International Journal of Artificial Intelligence in Education, 26(1), 431-447. https://doi.org/10.1007/s40593-015-0073-9

Vygotsky, L. S. (1978). Mind in society: The development of higher psychological processes. Cambridge, MA, USA: Harvard University Press.

West, R. E. (2010). A student's guide to strengthening an online community. TechTrends, 54(5), 69

Wise, A. F., \& Chiu, M. M. (2011). Analyzing temporal patterns of knowledge construction in a role-based online discussion. Computer-Supported Collaborative Learning, 6, 445-470. https://doi.org/10.1007/s11412-011-9120-1

Wise, A. F., Hausknecht, S. N., \& Zhao, Y. (2014). Attending to others' posts in asynchronous discussions: Learners' online "listening" and its relationship to speaking. International Journal of Computer-Supported Collaborative Learning, 9(2), 185-209. https://doi.org/10.1007/s11412-014-9192-9 